\title{
Personality and college student subjective wellbeing: a domain-specific approach
}

\author{
Don C. Zhang \\ Louisiana State University \\ Tyler L. Renshaw \\ Utah State University
}

\begin{abstract}
Author Note
Correspondence concerning this study should be sent to Don Zhang at zhang1@1su.edu.

Don C. Zhang, PhD, Department of Psychology, Louisiana State University, Baton Rouge, LA.

Tyler L. Renshaw, PhD, Department of Psychology, Utah State university, Logan, UT.

We declare no financial conflicts of interest in conducting or reporting this work.
\end{abstract}

\section{Version Note}

Final draft of the manuscript accepted for publication in Journal of Happiness Studies.

This version is not the copy of record and may not exactly replicate the final, authoritative version of the article. 


\begin{abstract}
Domain-specific measures of subjective wellbeing are valuable tools for assessing the mental health of college students. In this study, we examined relations between Big Five personality traits and college students' subjective wellbeing (SWB) using a college-specific measure: The College Student Subjective Wellbeing Questionnaire (CSSWQ). Using a latent variable modeling approach called bifactor analysis, we found that the general college wellbeing factor was best predicted by agreeableness and extraversion whereas the specific dimensions of college SWB were differentially predicted by conscientiousness and neuroticism. Specifically, conscientiousness best predicted academic satisfaction and efficacy whereas neuroticism best predicted students' connectedness to the university. The results suggest that the profile of a flourishing college student is extraverted and agreeable. This study illustrates the methodological advantage of using a domain-specific measure of SWB and bifactor modeling to shed light on the unique relations between personality and various aspects of college students' mental health. Keywords: Big Five personality, college subjective wellbeing, positive psychology, bifactor analysis, psychometrics
\end{abstract}




\section{Personality and college student subjective wellbeing: a domain-specific approach}

Subjective wellbeing (SWB) refers to a person's self-perceptions of so-called "positive" inner events, which are defined as personally or socially desirable patterns of thinking (cognition) and feeling (emotion). The SWB of college students is a growing area of concern given the rise in mental health issues in higher education (Beiter et al., 2015; Twenge, Joiner, Rogers, \& Martin, 2018). Moreover, poor SWB often precedes severe mental health and behavioral issues such as depression, suicidality, and college dropout (Keyes, Dhingra, \& Simoes, 2010; Keyes et al., 2012; Renshaw \& Bolognino, 2016). Accurately identifying highrisk individuals may inform targeted intervention and prevention efforts.

Personality individual differences are one of the strongest predictors of SWB (Friedman, Kern, \& Reynolds, 2010; Steel, Schmidt, \& Shultz, 2008). In their review, Lucas and Diener (2009) concluded “the most important factor in determining a person's SWB appears to be the personality with which he or she is born" (p.83). Accordingly, a growing body of work has examined the associations between college students' personality and SWB. Existing research, however, either uses a domain-general measure (e.g., life satisfaction, Joshanloo \& Afshari, 2011; Lounsbury, Saudargas, Gibson, \& Leong, 2005) or narrow measures in specific collegial contexts (e.g., satisfaction with major, Logue, Lounsbury, Gupta, \& Leong, 2007). Both approaches are incomplete because domain-general measures overlook the domain-specific aspects of the college experience, whereas narrow measures in a single college context discount the multi-dimensional aspects of college thriving (Kim, Furlong, Dowdy, \& Felix, 2014; Renshaw \& Bolognino, 2016). In other words, neither approaches fully illustrate the association 
between personality and college students' SWB because the criterion measures are either too general or too specific.

In the present study, we examined the associations between Big Five personality and college student SWB using a multi-dimensional domain-specific measure: the College Student Subjective Wellbeing Questionnaire (CSSWQ, Renshaw, 2016). The CSSWQ measures students' SWB in four specific college contexts: 1) Academic Efficacy, 2) College Gratitude, 3) School Connectedness, and 4) Academic Satisfaction. Given the unique social aspects of the college environment and the developmental needs of early adults, the profile of a psychologically flourishing college student may differ from the general population. A domain-specific scale, therefore, is more appropriate for measuring college students' SWB. We also use a bifactor analysis to model the criterion construct (Reise, 2012). Bifactor analysis is a type of confirmatory factor analysis that simultaneously models the general and specific factors of a multi-dimensional construct such as SWB. This technique allows us to examine - more clearly the associations between each personality trait with both the general- and specific- factors of the CSSWQ, thereby shedding light on the unique relations between personality and various dimensions of college students' SWB.

\section{Background}

\section{Subjective Wellbeing}

Subjective wellbeing is a core construct in positive psychology (Seligman \& Csikszentmihalyi, 2014) and conceptualized as a subtype of human wellbeing (cf. Biglan, Flay, Embry, \& Sandler, 2012). SWB generally consists of one's overall life satisfaction, general tendency to experience positive affect, and a global sense of happiness (Diner, Oishi, \& Lucas, 
2009). Other approaches have expanded traditional conceptualizations of SWB to target specific domains of human functioning. For example, Seligman's (2012) PERMA model operationalizes SWB via self-reports of (P) positive emotion, (E) engagement, (R) relationships, (M) meaning, and (A) accomplishment (e.g., Kern, Waters, Adler, \& White, 2015). Similarly, Ryff and Keyes (1995) proposed a six-factor model of wellbeing with a single higher-order factor representing psychological wellbeing. Recent research has found evidence for a higher order general wellbeing factor at the apex of the various SWB models (Chen, Jing, Hayes, \& Lee, 2013).

To date, the majority of research on SWB has used domain-general approaches (i.e., experienced across life contexts) to investigate the relationship between SWB and other valued life outcomes. Findings from this line of work have demonstrated, for example, that general positive affectivity is a significant predictor of physical health symptoms (Pettit, Kline, Gencoz, Gencoz, \& Joiner Jr, 2001), that general self-efficacy has a positive influence on work performance (Parker, Jimmieson, \& Johnson, 2013), and that general life satisfaction predicts momentary measures of psychological and physiological stress (Smyth, Zawadzki, Juth, \& Sciamanna, 2017).

Another, smaller line of work was undertaken to evaluate the relationship between domain-specific SWB (i.e., experienced within specific life domains, such as school or work) and valued life outcomes. Studies in this area have shown that multidimensional domain-specific SWB measures are psychometrically defensible (e.g., Gilman, Huebner, \& Laughlin, 2000; Singh \& Aggarwal, 2018), and that responses to domain-specific measures can have variable associations with responses to domain-general measures of wellbeing (e.g., Oishi \& Diener, 2001). Moreover, domain-specific and general measures of wellbeing can have differential 
power for predicting domain-specific outcomes (e.g., Datu, 2018; Kim et al., 2014; Renshaw \& Bolognino, 2016).

One relatively new measure in the study of college students is the College Student Subjective Wellbeing Questionnaire (CSSWQ), which was developed by Renshaw and Bolognino (2016) to measure young adults' multidimensional wellbeing within university settings. Like other multidimensional measures of SWB, the CSSWQ was conceived with the intent of functioning as a screening instrument that allows practitioners to gauge wellbeing at the population level and, potentially, identify persons with poorer wellbeing that might warrant intervention or supports. The authors found that the overall college wellbeing score was a stronger predictor of students' academic achievement than domain-general wellbeing measures (Renshaw \& Bolognino, 2016). The multi-dimensionality nature of the instrument also revealed unique associations between specific SWB dimensions and domain-specific outcomes. For example, grade point average was most strongly associated with academic satisfaction and academic efficacy dimensions of the CSSWQ whereas as general mental health outcomes such as depression was more strongly associated with school connectedness (Renshaw, 2018).

Another realm of research independently supports the predictive power of domainspecific SWB, sans comparisons with domain-general SWB. This is illustrated in studies validating school-specific measures of SWB with adolescents, which have repeatedly shown that these indicators are viable predictors of a variety of valued life outcomes, including standardized test scores and grade-point average (Renshaw \& Chenier, 2018), substance use and problem behaviors (Arslan \& Renshaw, 2018) as well as positive social and academic engagement at school (Renshaw, Cook, \& Long, 2015). In sum, there is ample evidence illustrating the added 
value of domain-specific multi-dimensional measures of SWB as a predictor of valuable behavioral and mental health outcomes in their respective settings (e.g., colleges).

\section{Personality and Subjective Wellbeing}

Compared to situational and life circumstances, personality dispositions play a much more significant role in determining a person's subjective wellbeing (Diener, Suh, Lucas, \& Smith, 1999; Hentschel, Eid, \& Kutscher, 2017; Reyes-García, Angelsen, Shively, \& Minkin, 2018). Two meta-analyses have examined the relations between major personality traits and SWB (DeNeve \& Cooper, 1998; Steel et al., 2008). Although the earlier meta-analysis found weak to modest correlations, Steel and colleagues - using more validated measures of the Big Five personality (Costa \& McCrae, 1992) - found much higher correlations between personality and SWB.

Wilson (1967) characterized a happy person as "extraverted, optimistic, worry free." Accordingly, research has found extraversion and neuroticism to be the most consistent predictors of SWB (Diener et al., 1999; Lauriola \& Iani, 2017; Steel et al., 2008). Across six indicators of SWB, extraversion and neuroticism had meta-analytic correlations ranging from $r$ $=.18$ to $r=.53$ (Steel et al., 2008). The association between personality and SWB has been attributed to temperament theories (Costa \& McCrae, 1980; Gray, 1970; Tellegen et al., 1988). According to Gray, people who are high on extraversion are more sensitive to reward signals, which result in greater positive emotions when being exposed to positive stimuli. In contrast, people who are high on neuroticism are more sensitive to negative stimuli. Indeed, a number of studies have attributed the association between personality and subjective wellbeing to physiological processes (Lucas \& Baird, 2004; Smillie, Cooper, Wilt, \& Revelle, 2012). Other 
personality traits such as conscientiousness and agreeableness also show modest relations with specific facets of subjective wellbeing. Correlations between agreeableness to SWB, for instance, ranged from $r=.12$ with positive affect, to $r=.30$ with overall happiness (Steel et al., 2008). Similarly, conscientiousness was negatively correlated with negative affect and positively correlated with quality of life.

Personality and College Student SWB. Studies examining the relations between personality and college student SWB have revealed a similar pattern of associations. Joshanloo and Afshari (2011), for example, found that extraversion and neuroticism - but not the other three Big Five dimensions - were the primary predictors of college students' life satisfaction. Similarly, Lounsbury et al., (2005) found extraversion and neuroticism to be the strongest predictors of life satisfaction (also see Harris, English, Harms, Gross, \& Jackson, 2017; James, Bore, \& Zito, 2012). Interestingly, the authors did not find extraversion to be a significant predictor of college satisfaction. However, their measure of college satisfaction contained primarily academically oriented items and did not contain social or emotionally related dimensions of wellbeing. Using a more narrow measure, Logue et al., (2007) found that extraversion, neuroticism, and conscientiousness primarily predicted college students' satisfaction with major.

Some studies have adopted a multi-dimensional conceptuality of SWB. Joshanloo and Nosratabadi (2009), for instance, examined the relations between the Big Five personality traits with three dimensions of wellbeing: psychological wellbeing, social wellbeing, and emotional wellbeing. The authors, however, categorized students into discrete groups varying in mental health based on an aggregation of the wellbeing dimensions. Likewise, Marino et al. (2016) 
examined the relations between personality and positive mental health (PMH) using a multidimensional instrument: the Social and Emotional Health Survey (Furlong, You, Renshaw, Smith, \& O'Malley, 2014). The authors found that extraversion was significantly related to all four dimensions of positive mental health; agreeableness significantly predicted emotional competence, belief-in-others, and engaged living. Other Big Five traits showed modest associations with the mental health domains. Interestingly, emotional stability was not significantly related with any of the PMH domains. However, the authors only examined the associations between the Big Five with each dimension of PMH. Moreover, these studies also used domain-general measures of SWB, and therefore, may not adequately reflect collegespecific aspects of student wellbeing.

The analytical strategies of the aforementioned studies are limited given the multidimensionality of the criteria. The observed association between personality and an aggregate measure of wellbeing (e.g., Joshanloo and Nosratabadi, 2009) does not provide insight into the unique contributions of the specific dimensions. In contrast, associations between personality to specific wellbeing dimensions (e.g., Marino et al., 2016) are ambiguous in terms of the independent role of the general factor. In other words, it is uncertain whether the observed association between a personality trait (e.g., extraversion) and a specific dimension of SWB (e.g., belief-in-self) is attributed to the dimension itself, or the general factor of positive wellbeing.

\section{General vs. Specific SWB}

Most multi-dimensional psychological constructs consist of a general component (e.g., general mental ability) and specific dimensions (e.g., verbal ability, reasoning ability, etc). 
Predictions are maximized when the breadth of the predictor is matched with the breadth of the criterion (Hogan \& Roberts, 1996). McAbee and Oswald (2013), for example, found that broad personality dimensions such as conscientiousness differentially predicted measures of academic performance that vary in bandwidth. Specifically, conscientiousness most strongly predicted broad measures of academic performance (grade point average), and only weakly predicted narrow performance dimension such as responsibility, ethics, and learning orientation. Similarly, previous meta-analytic investigations also revealed disparate associations between the five factors of personality and specific dimensions of subjective well-being (e.g., Steel et al., 2008). Their findings suggest that the associations between personality and subjective wellbeing may be enhanced by examining theoretically relevant linkages.

In multidimensional measures such as the CSSWQ, the overall scale score (e.g., overall wellbeing) is obtained by aggregating - or taking the average - across the lower order indicators (e.g., Renshaw \& Bolognino, 2016). This approach is problematic because it leads to conceptual ambiguity: the composite score captures both the shared variance across lower order facets as well as the unique variance among the facets. Therefore, it is unclear whether the observed relationship between a predictor (e.g., extraversion) and outcome (e.g., aggregated college subjective wellbeing score) is attributed to a person's global evaluation of college SWB or one of the lower order facets (e.g., school connectedness).

When predicting multi-dimensional criteria, it is important that appropriate methodology is used (e.g., Caspi, Roberts, \& Shiner, 2005; Chen, Hayes, Carver, Laurenceau, \& Zhang, 2012). In this study, we examine the differential predictions of the five factors of personality on both general and specific factors of college subjective wellbeing using bifactor analysis. Bifactor 
analysis is a form of confirmatory factor analysis where the items are simultaneously loaded onto a general factor and orthogonal lower-order factors. Previous application of the bifactor approach have primarily focused on the predictor construct, where the goal was to examine incremental prediction of the general and lower order factors of the predictor variable on the criterion (e.g., (Highhouse, Nye, Zhang, \& Rada, 2017; Mcabee, Oswald, \& Connelly, 2014). However, bifactor analysis can also be used to explore relationships between a set of predictors with the general and specific factors of the criterion, such as the relationship between personality and college subjective wellbeing.

\section{Bifactor Analysis}

Bifactor analysis is typically used to model the factor structure of multi-dimensional constructs where there exist a general higher-order factor and specific lower-order facets. Bifactor models have been used in intelligence (Gustafsson \& Balke, 1993), personality (DeYoung, Peterson, Séguin, \& Tremblay, 2008), and general subjective wellbeing (Chen et al., 2013). Bifactor models are appropriate when (1) there is a general factor that accounts for common variance across indicators (items); (2) there are multiple related but distinct domainspecific factors; and (3) researchers are interested in both the general factor and domain-specific factors, such as the broad and narrow aspects of subjective well-being (Chen, West, \& Sousa, 2006).

Bifactor models are comparable to a second-order model, which was used as the analytical framework in the development of the original CSSWQ (Renshaw \& Bolognino, 2016). Figure 1 compares a bifactor model of the CSSWQ to a second-order model. In a bifactor model, the indicators simultaneously load on to the orthogonal lower-order factors and the general factor 
of wellbeing (Figure 1a). The lower-order factors are represented by the residual variance in the indicators after accounting for the general factor. In other words, the residual variance for the lower-order factors can be conceptualized as the unique variance in the items captured by each specific dimension of SWB after accounting for the general factor. According to Reise, Moore, and Haviland (2010), lower- and higher-order factors in a bifactor model are on "equal conceptual footing and compete for explaining item variance - neither is 'higher' or 'lower' than the other" (p. 547).

In second-order models, the items are modeled as indicators of the lower-order factors. Furthermore, the lower-order factors are modeled as reflections of the general factor (Figure 1b). Second-order models are a variant of the bifactor model where the item loadings to the general factor is constrained to zero; conversely in a bifactor model, the item loadings to the general factor is free to vary. According to Chen et al., (2006), second-order models are more restricted than bifactor models. Moreover, second-order models suffer from conceptual ambiguity in modeling multi-dimensional constructs. Specifically, the general factor in a second-order model does not separate the unique variance of the lower-order facets from the shared variance.

Bifactor models are more theoretically appropriate than second-order models for modeling multi-dimensional constructs. In the bifactor model, specific factors are constrained to be uncorrelated with the general factor. This allows the model to estimate the specific latent factors (academic satisfaction, gratitude, etc) after partialing out variance attributed to the general factor of college SWB. In contrast, the second-orders models are not capable of fully separating the general factor and lower order facets. This is because, in a second-order model, the specific factors are also represented by unique variances (disturbances) of the general factor: 
thus, leading to conceptual ambiguity. In other words, the specific factors in a second-order model are contaminated by the general factor. Likewise, individual scale scores derived from taking the arithmetic sum (or average) of the item scores are equally contaminated by both general and specific factors (Chen et al., 2012).

\section{Present Study}

In the present study, we use a latent variable modeling approach to examine the associations between personality and college student SWB. First, using bifactor analysis, we accurately model both the general and specific components of the CSSWQ. Next, using path analysis, we examine the unique associations between the Big Five personality and both the general and specific dimensions of college SWB. The combination of a college-specific measure and appropriate methodology allows us to accurately examine the role of personality in the subjective wellbeing of college students.

\section{Methods}

\section{Procedure}

Data were gathered at two separate time points from students enrolled in psychology classes at a large southern university in the United States as part of a larger data collection effort. We recruited participants using the university's human subjects pool (SONA) and respondents received nominal course credit for their participation. All of the instruments and procedures reported in the paper were approved by the Institutional Review Board (IRB) at the first author's institution. Each survey took approximately ten minutes to complete. Participants completed the Big Five Inventory (BFI, John, Donahue, \& Kentle, 1991) and demographic variables at Time 1; 
(CSSWQ; Renshaw, 2016). The separation of predictor and criterion variables reduces the effect of common measurement variance (Vandenberg \& Lance, 2000). All survey material was administered using Qualtrics ${ }^{1}$, an online survey platform. Participants completed the survey over the internet. Given that the project received the "Exempt" status by the IRB, written or oral consent was waived. Instead, after reviewing the consent form on the electronic survey, the participants were explicitly told to "only continue to the next page if you consent to the procedures described above."

\section{Sample}

The first survey was completed by 434 college students during the first month of the fall semester. The follow-up survey containing was completed approximately two months later by 249 participants. Across both surveys, we included five attention check questions to reduce response acquiescence (e.g., "if you are still paying attention, please respond to this question with 'strongly disagree"”; DeSimone, Harms, \& DeSimone, 2015). Participants who failed more than one question were dropped from the survey. This process yielded a total of 181 participants who completed both surveys. The final sample was primarily female (82\%) and Caucasian (83\%). The participants were evenly distributed across class standings $(28 \%$ of the participants were Freshman, 20\% Sophomore, 27\% Juniors, and 25\% Seniors).

\section{Measures}

Big Five Inventory (BFI). The BFI is a 44-item self-report measure of the Big Five personality (John et al., 1991). It measures the five personality traits: extraversion (e.g., "tends to be quite", agreeableness (e.g., "has a forgiving nature"), conscientiousness (e.g., "tends to be

\footnotetext{
${ }^{1}$ https://www.qualtrics.com/
} 
lazy"), neuroticism (e.g., "can be moody"), and openness to experience (e.g., "values artistic, aesthetic experience"). Participants were presented with short statements that describe aspects of their personality and indicated, on a 5 -point Likert scale $(1=$ strongly disagree to $5=$ strongly agree), the degree to which they agree or disagree with each statement.

College Student Subjective Wellbeing Questionnaire (CSSWQ). The revised version of the CSSWQ consists of 16 self-report items that comprise four subscales: Academic Efficacy (4 items), College Gratitude (4 items), School Connectedness (4 items), and Academic Satisfaction (4 items). All CSSWQ items are arranged along the same 7-point Likert-type response scale $(1=$ strongly disagree to $7=$ strongly agree $)$ and are directly phrased to measure the constructs of interest (e.g., "I am an organized and effective student" and "I am happy with how I've done in my classes") (Renshaw \& Bolognino, 2016; Renshaw, 2016). Overall wellbeing score was calculated by taking the average of all scale items.

\section{Results}

Table 1 contains the scale reliabilities and intercorrelations between the variables. The results showed that the four dimensions of college subjective wellbeing are strongly correlated with each other, and with the overall composite score for college subjective wellbeing. Four of the five dimensions of personality, except for openness to experience, predicted overall subjective wellbeing.

Next, we examined the fit of the bifactor model for the CSSWQ. In addition to the bifactor model, we also tested alternative theoretical models (Credé \& Harms, 2015). Table 2 contains the model fit indices for the one-factor, four-factor, second-order factor, and bifactor model of the CSSWQ. All analyses were done with the package lavaan in R using maximum 
likelihood estimation. The one-factor model, which only assumes a general factor of subjective wellbeing, had poor fit. The four-factor model fit the data better than a one-factor model, but the fit indices still did not meet standard criteria for acceptable model fit based on established criteria (Hu \& Bentler, 1999; MacCalum, Browne, \& Sugawara, 1996). The RMSEA, for example, was greater than 0.06 , and the CFI and TLI were both less than .95 .

Although the CSSWQ was originally conceptualized as a second-order model (Renshaw $\&$ Bolognino, 2016), some of the fit indices for the second-order model were unsatisfactory. For example, the RMSEA for the second-order model was greater than .06; $90 \%$ confidence interval estimates did not include $.05[0.073-0.103]$, which is suggested as a criteria for good model fit (Steiger, 1990). Moreover, CFI was less than .95, which is required for excellent fit (Hu \& Bentler, 1999). The bifactor model had excellent fit with the data across all model fit indices (Table 2). CFI and TLI were both at or above 0.95 . Although RMSEA did not reach the conventional cut-off criteria of 0.06 recommended by $\mathrm{Hu}$ and Bentler (1999), the $90 \%$ confidence interval did include 0.05 [0.048 - 0.083], which is considered acceptable according to Steiger (1990). The change in chi-squared between the second-order and bifactor model was also statistically significant. Theoretical considerations also suggest that a bifactor structure is more representative of the multi-dimensional nature of subjective wellbeing (Chen et al., 2006).

Table 3 contains the item loadings in the bifactor model. Item loading estimates showed that all items loaded to both the general wellbeing factor and the lower order factors. It is notable that - on average - most of the items loaded more strongly to the lower order factors than the general factor. The results suggest that even after accounting for the shared variance across items, there is still strong evidence for the existence of lower order facets. 


\section{Associations Between Big Five and College SWB}

Next, we examined the associations between the five factors of personality to both the general and specific factors of college student SWB. The path model fit the data well (Table 2). Table 4 contains the standardized path coefficients between the latent factors of CSSWQ and the Big Five personality traits. The pattern of associations between personality and SWB in the path model is noticeably different from the bivariate relations. First, we find that extraversion consistent with previous theory and research - was the strongest predictor of the general factor in the bifactor model. Neuroticism, however, did not predict the general wellbeing factor. Other facets of the Big Five did, however, predict the narrow facets of college SWB. Agreeableness positively predicted gratitude; conscientiousness positively predicted academic efficacy and academic satisfaction, and neuroticism negatively predicted school connectedness. Openness to experience was not associated with any of the latent factors of the CSSWQ.

\section{Discussion}

In this paper, we sought to examine the association between the Big Five personality traits and college students' subjective wellbeing. Past research has been limited due to the use of

overly broad or highly specific measures of SWB. To better illuminate the role of personality and college student SWB, we used a domain-specific measure: The College Student Subjective Wellbeing Questionnaire. Furthermore, using a bifactor analysis, we examined the unique associations between each personality factor and both the specific and general factors of college SWB.

Whereas previous research has found conscientiousness to be a significant predictor of student SWB, our results show that conscientiousness is related only to academic related 
dimensions of the CSSWQ such as academic satisfaction and academic efficacy. These results are consistent with other research demonstrating the role of conscientiousness on academic performance (McAbee \& Oswald, 2013). However, after accounting for the specific academic related domains, conscientiousness was no longer associated with the general wellbeing factor. The lack of an association between neuroticism and general wellbeing was puzzling because neuroticism is one of the most consistent predictor of subjective and psychological wellbeing (Lucas \& Diener, 2009; Takebayashi, Tanaka, Sugiura, \& Sugiura, 2018, but see Marino et al., 2016). We did, however, found an association between neuroticism and school connectedness, which is arguably more affectively driven. Given that neurotic individuals tend to appraise experience more negatively, it is reasonable to expect that students who are high on neuroticism tend to perceive lower support and affiliation with their university. The observed association is also noteworthy given that school connectedness was one of the strongest predictors of depression (Renshaw 2018). Our suggest that a school connectedness may serve as an intermediate link between neuroticism and depression of college students (Grevenstein, AguilarRaab, \& Bluemke, 2018; Weissman, Prusoff, \& Klerman, 1978).

The observed association between agreeableness and the general wellbeing factor is particularly noteworthy. Some previous studies have generally shown that agreeableness is unrelated to college student wellbeing (James et al., 2012; Logue, Lounsbury, Gupta, \& Leong, 2007; Lounsbury, Saudargas, et al., 2005). Likewise, studies in the general population have found agreeableness only weakly associated with SWB (Steel et al., 2008). One possible explanation for our finding is the domain specificity of the measure, which better reflects students' experience in college. College environments are socially oriented. Therefore, students' 
overall wellbeing may be more contingent on the quality of their social relationships, which better align with agreeableness. Said another way, students who are more dispositionally inclined to "get along" may experience better overall wellbeing in college. Indeed, past research has found that agreeableness is the strongest predictor of friendship quality in college students (Demır \& Weitekamp, 2007), and others have found that social experiences serve as an important explanatory variable for college students life satisfaction (Harris et al., 2017). The role of agreeableness for college SWB is consistent with trait-activation theory (Tett \& Guterman, 2000). According to trait-activation theory, personality traits are manifested in situations where the environment is congruent with the trait. For example, openness to experience is more predictive of job performance in occupations where creativity is most valued (Judge \& Zapata, 2015). Relatedly, in a college environment where social interactions are ubiquitous, it comes as no surprise that extraversion and agreeableness are the most important predictors of general college wellbeing.

Deviations in the associations observed using bivariate correlations and latent variable modeling also highlight the benefit of a bifactor analysis when the researcher is concerned with predicting a multi-dimensional construct. Whereas the overall student wellbeing score - using an aggregation method - was significantly predicted by four of the five personality traits, the bifactor path analysis revealed significant associations with only extraversion and agreeableness. The differences in the magnitude of associations are also noteworthy. Bivariate correlations, for example, showed agreeableness and conscientiousness to be the strongest predictors of overall subjective wellbeing; whereas bifactor analysis showed conscientiousness was unrelated with the general wellbeing factor and was most strongly associated with academic efficacy and academic 
satisfaction. Although extraversion was only moderately correlated with each of the dimensions scores in the CSSWQ using bivariate correlations, bifactor analysis showed that it is one of the primary predictors of the general wellbeing factor.

Our results speak to the importance of using appropriate measures and methodology predicting multi-dimensional measures. Arguably, past research has overlooked the unique associations between personality and specific dimensions of college SWB because the statistical models did not account for the shared variance across dimensions (e.g., Marino et al., 2016). Therefore, the observed associations may either be attenuated or inflated depending on the role of the general factor. After accounting for shared variance across dimensions of SWB (general wellbeing factor) using bifactor analysis, we were able to identify unique associations between each specific domain and the Big Five as well as the true association between the Big Five and college students' general wellbeing. Based on these findings, we suggest that when researchers are concerned with predicting multi-dimensional criteria (e.g., SWB), a bifactor modeling approach should be considered if the researcher is interested in disentangling the unique associations between the predictor with both the specific and general factors of the criteria.

Our research also calls for further inquiry into the relations between personality and SWB more broadly. Existing research has often overlooked the hierarchical nature of SWB. As demonstrated by Chen et al., (2013), despite multiple conceptualizations of wellbeing, there exist a higher order general factor in addition to specific factors of wellbeing. Future research should examine associations between personality and the general wellbeing factor as well as the specific wellbeing dimensions. As illustrated in our results, when higher- and lower- order dimensions of wellbeing are simultaneously considered, the observed association with personality can differ 
considerably. Examining these associations can provide more accurate estimates for the role of personality as well as evidence of for the construct validity of the general wellbeing factor.

A limitation of our study is that the general wellbeing factor may represent common method variance in the measure (Podsakoff, MacKenzie, Lese, \& Podsakoff, 2003). In other words, the shared variance across indicators may be the result of using the same method of measurement (self-report). Although CMV can be modeled with a bifactor approach in the literature (Johnson, Rosen, \& Djurdjevic, 2011), we believe that the general factor in our bifactor model does not simply represent method factor. Specifically, the path model shows that the general factor of wellbeing was predicted by theoretically relevant constructs such as extraversion measured at a separate time point. There are no theoretical reasons for why extraversion - measured at another time - would be positively associated with the general factor if it simply represented a method factor. A second limitation is the lack of narrow personality measures. Past research has found narrow facets of the Big Five (e.g., creativity, patience, etc.) may provide incremental prediction of narrow academic outcomes over and above the broad traits (Lounsbury et al., 2005; McAbee et al., 2014). Future research should more closely examine the relations between narrow facets of personality and specific factors of college SWB. Individual difference characteristics outside of the traditional Big Five such as resiliency, risk propensity, and mindfulness should also be considered (Dubas, Baams, Doornwaard, \& van Aken, 2017; Grevenstein et al., 2018; Zhang, Highhouse, \& Nye, 2018). A third limitation of the study is the demographic characteristics of the sample, which consisted of mostly female undergraduate students in psychology. Future research should extend these findings to a more representative sample of the student body to enhance the generalizability of our findings. Finally, 
future research should examine the incremental prediction of the narrow facets of the CSSWQ over the general factor of predicting academic outcomes. Although Renshaw (2016) found that the aggregated student wellbeing score positively predicted outcomes such as depression and GPA, it is uncertain if the relationship is driven by the general wellbeing factor or the specific facets. Future research should examine the incremental prediction of the general wellbeing factor on broad outcomes related to general wellbeing (e.g., satisfaction with life). Relatedly, future research should further explore the relations between the general wellbeing factor and other broad academic performance outcomes (e.g., Schmitt \& Bradburn, 2019). A bifactor approach would shed light on the predictive validity of broad and narrow dimensions of college wellbeing on academic performance and student mental health.

In conclusion, our paper used a bifactor model to examine the predictive validity of the Big Five personality traits on both specific and general factors of college student wellbeing. We showed that there exists a general factor of college subjective wellbeing that accounts for shared variance across the specific dimensions. And, the general and specific dimensions of college SWB are differentially predicted by the Big Five personality traits: providing novel insights into the role of personality on college students' wellbeing. 


\section{References}

Arslan, G., \& Renshaw, T. L. (2018). Student Subjective Wellbeing as a Predictor of Adolescent Problem Behaviors: a Comparison of First-Order and Second-Order Factor Effects. Child Indicators Research, 11(2), 507-521.

Beiter, R., Nash, R., McCrady, M., Rhoades, D., Linscomb, M., Clarahan, M., \& Sammut, S. (2015). The prevalence and correlates of depression, anxiety, and stress in a sample of college students. Journal of Affective Disorders, 173, 90-96.

Biglan, A., Flay, B. R., Embry, D. D., \& Sandler, I. N. (2012). The critical role of nurturing environments for promoting human well-being. American Psychologist, 67(4), 257.

Caspi, A., Roberts, B. W., \& Shiner, R. L. (2005). Personality Development: Stability and Change. Annual Review of Psychology, 56(1), 453-484.

https://doi.org/10.1146/annurev.psych.55.090902.141913

Chen, F. F., Hayes, A., Carver, C. S., Laurenceau, J.-P., \& Zhang, Z. (2012). Modeling general and specific variance in multifaceted constructs: A comparison of the bifactor model to other approaches. Journal of Personality, 80(1), 219-251.

Chen, F. F., Jing, Y., Hayes, A., \& Lee, J. M. (2013). Two concepts or two approaches? A bifactor analysis of psychological and subjective well-being. Journal of Happiness Studies, 14(3), 1033-1068.

Chen, F. F., West, S., \& Sousa, K. (2006). A Comparison of Bifactor and Second-Order Models of Quality of Life. Multivariate Behavioral Research, 41(2), 189-225. https://doi.org/10.1207/s15327906mbr4102_5 
Costa, P. T., \& McCrae, R. R. (1980). Influence of extraversion and neuroticism on subjective well-being: Happy and unhappy people. Journal of Personality and Social Psychology, 38(4), 668-678. https://doi.org/10.1037/0022-3514.38.4.668

Costa, P. T., \& McCrae, R. R. (1992). Four ways five factors are basic. Personality and Individual Differences, 13(6), 667-673. https://doi.org/10.1016/0191-8869(92)90236-I

Credé, M., \& Harms, P. D. (2015). 25 years of higher-order confirmatory factor analysis in the organizational sciences: A critical review and development of reporting recommendations. Journal of Organizational Behavior, 36(6), 845-872. https://doi.org/10.1002/job.2008

Datu, J. A. D. (2018). Flourishing is Associated with Higher Academic Achievement and Engagement in Filipino Undergraduate and High School Students. Journal of Happiness Studies, 19(1), 27-39. https://doi.org/10.1007/s10902-016-9805-2

Demır, M., \& Weitekamp, L. A. (2007). I am so happy'cause today I found my friend: Friendship and personality as predictors of happiness. Journal of Happiness Studies, 8(2), $181-211$.

DeNeve, K. M., \& Cooper, H. (1998). The happy personality: A meta-analysis of 137 personality traits and subjective well-being. Psychological Bulletin, 124(2), 197-229. https://doi.org/10.1037/0033-2909.124.2.197

DeSimone, J. A., Harms, P. D., \& DeSimone, A. J. (2015). Best practice recommendations for data screening: Data Screening. Journal of Organizational Behavior, 36(2), 171-181. https://doi.org/10.1002/job.1962 
DeYoung, C. G., Peterson, J. B., Séguin, J. R., \& Tremblay, R. E. (2008). Externalizing behavior and the higher order factors of the Big Five. Journal of Abnormal Psychology, 117(4), 947.

Diener, E., Suh, E. M., Lucas, R. E., \& Smith, H. L. (1999). Subjective well-being: Three decades of progress. Psychological Bulletin, 125(2), 276-302. https://doi.org/10.1037/0033-2909.125.2.276

Dubas, J. S., Baams, L., Doornwaard, S. M., \& van Aken, M. A. G. (2017). Dark personality traits and impulsivity among adolescents: Differential links to problem behaviors and family relations. Journal of Abnormal Psychology, 126(7), 877-889. https://doi.org/10.1037/abn0000290

Friedman, H. S., Kern, M. L., \& Reynolds, C. A. (2010). Personality and health, subjective wellbeing, and longevity. Journal of Personality, 78(1), 179-216. https://doi.org/10.1111/j.1467-6494.2009.00613.x

Furlong, M. J., You, S., Renshaw, T. L., Smith, D. C., \& O’Malley, M. D. (2014). Preliminary development and validation of the social and emotional health survey for secondary school students. Social Indicators Research, 117(3), 1011-1032.

Gilman, R., Huebner, E. S., \& Laughlin, J. E. (2000). A first study of the Multidimensional Students' Life Satisfaction Scale with adolescents. Social Indicators Research, 52(2), $135-160$.

Gray, J. A. (1970). The psychophysiological basis of introversion-extraversion. Behaviour Research and Therapy, 8(3), 249-266. https://doi.org/10.1016/0005-7967(70)90069-0 
Grevenstein, D., Aguilar-Raab, C., \& Bluemke, M. (2018). Mindful and resilient? Incremental validity of sense of coherence over mindfulness and Big Five personality factors for quality of life outcomes. Journal of Happiness Studies, 19(7), 1883-1902.

Gustafsson, J.-E., \& Balke, G. (1993). General and specific abilities as predictors of school achievement. Multivariate Behavioral Research. https://doi.org/10.1207/s15327906mbr2804_2

Harris, K., English, T., Harms, P. D., Gross, J. J., \& Jackson, J. J. (2017). Why are Extraverts more Satisfied? Personality, Social Experiences, and Subjective Well-being in College: Extraverts and social experience. European Journal of Personality, 31(2), 170-186. https://doi.org/10.1002/per.2101

Hentschel, S., Eid, M., \& Kutscher, T. (2017). The influence of major life events and personality traits on the stability of affective well-being. Journal of Happiness Studies, 18(3), 719741.

Highhouse, S., Nye, C. D., Zhang, D. C., \& Rada, T. B. (2017). Structure of the Dospert: Is There Evidence for a General Risk Factor? Journal of Behavioral Decision Making, 30(2), 400-406. https://doi.org/10.1002/bdm.1953

Hogan, J., \& Roberts, B. (1996). Issues and non-issues in the fidelity-bandwidth trade-off. Journal of Organizational Behavior, 17(6), 627-637.

Hu, L., \& Bentler, P. M. (1999). Cutoff criteria for fit indexes in covariance structure analysis: Conventional criteria versus new alternatives. Structural Equation Modeling: A Multidisciplinary Journal, 6(1), 1-55. 
James, C., Bore, M., \& Zito, S. (2012). Emotional Intelligence and Personality as Predictors of Psychological Well-Being. Journal of Psychoeducational Assessment, 30(4), 425-438. https://doi.org/10.1177/0734282912449448

John, O. P., Donahue, E. M., \& Kentle, R. L. (1991). The Big Five Inventory - Versions $4 a$ and 54. Berkeley, CA.

Johnson, R. E. R., Rosen, C. C., \& Djurdjevic, E. (2011). Assessing the impact of common method variance on higher order multidimensional constructs. The Journal of Applied Psychology, 96(4), 744-761. https://doi.org/10.1037/a0021504

Joshanloo, M., \& Afshari, S. (2011). Big Five Personality Traits and Self-Esteem as Predictors of Life Satisfaction in Iranian Muslim University Students. Journal of Happiness Studies, 12(1), 105-113. https://doi.org/10.1007/s10902-009-9177-y

Joshanloo, M., \& Nosratabadi, M. (2009). Levels of Mental Health Continuum and Personality Traits. Social Indicators Research, 90(2), 211-224. https://doi.org/10.1007/s11205-0089253-4

Judge, T. A., \& Zapata, C. P. (2015). The Person-Situation Debate Revisited: Effect of Situation Strength and Trait Activation on the Validity of the Big Five Personality Traits in Predicting Job Performance. Academy of Management Journal, 58(4), 1149-1179. https://doi.org/10.5465/amj.2010.0837

Kern, M. L., Waters, L. E., Adler, A., \& White, M. A. (2015). A multidimensional approach to measuring well-being in students: Application of the PERMA framework. The Journal of Positive Psychology, 10(3), 262-271. 
Keyes, C. L., Dhingra, S. S., \& Simoes, E. J. (2010). Change in level of positive mental health as a predictor of future risk of mental illness. American Journal of Public Health, 100(12), 2366-2371.

Keyes, C. L., Eisenberg, D., Perry, G. S., Dube, S. R., Kroenke, K., \& Dhingra, S. S. (2012). The relationship of level of positive mental health with current mental disorders in predicting suicidal behavior and academic impairment in college students. Journal of American College Health, 60(2), 126-133.

Kim, E. K., Furlong, M. J., Dowdy, E., \& Felix, E. D. (2014). Exploring the relative contributions of the strength and distress components of dual-factor complete mental health screening. Canadian Journal of School Psychology, 29(2), 127-140.

Lauriola, M., \& Iani, L. (2017). Personality, Positivity and Happiness: A Mediation Analysis Using a Bifactor Model. Journal of Happiness Studies, 18(6), 1659-1682. https://doi.org/10.1007/s10902-016-9792-3

Logue, C. T., Lounsbury, J. W., Gupta, A., \& Leong, F. T. L. (2007). Vocational Interest Themes and Personality Traits in Relation to College Major Satisfaction of Business Students. Journal of Career Development, 33(3), 269-295. https://doi.org/10.1177/0894845306297348

Logue, Christen T., Lounsbury, J. W., Gupta, A., \& Leong, F. T. L. (2007). Vocational Interest Themes and Personality Traits in Relation to College Major Satisfaction of Business Students. Journal of Career Development, 33(3), 269-295. https://doi.org/10.1177/0894845306297348 
Lounsbury, J. W., Hutchens, T., \& Loveland, J. M. (2005). An Investigation of Big Five Personality Traits and Career Decidedness Among Early and Middle Adolescents. Journal of Career Assessment, 13(1), 25-39. https://doi.org/10.1177/1069072704270272

Lounsbury, J. W., Saudargas, R. A., Gibson, L. W., \& Leong, F. T. (2005). An Investigation of Broad and Narrow Personality Traits in Relation to General and Domain-Specific Life Satisfaction of College Students. Research in Higher Education, 46(6), 707-729. https://doi.org/10.1007/s11162-004-4140-6

Lucas, R. E., \& Baird, B. M. (2004). Extraversion and Emotional Reactivity. Journal of Personality and Social Psychology, 86(3), 473-485. https://doi.org/10.1037/00223514.86 .3 .473

Lucas, R. E., \& Diener, E. (2009). Personality and wellbeing. In E. Diener (Ed.), The science of well-being (pp. 75-102). Neatherlands: Springer.

Marino, C., Vieno, A., Lenzi, M., Fernie, B. A., Nikčević, A. V., \& Spada, M. M. (2016). Personality Traits and Metacognitions as Predictors of Positive Mental Health in College Students. Journal of Happiness Studies, 1-15. https://doi.org/10.1007/s10902-016-9825y

McAbee, S. T., \& Oswald, F. L. (2013). The criterion-related validity of personality measures for predicting GPA: A meta-analytic validity competition. Psychological Assessment, 25(2), 532-544. https://doi.org/10.1037/a0031748

Mcabee, S. T., Oswald, F. L., \& Connelly, B. S. (2014). Bifactor Models of Personality and College Student Performance: A Broad Versus Narrow View. European Journal of Personality. https://doi.org/10.1002/per.1975 
Oishi, S., \& Diener, E. (2001). Re-Examining the General Positivity Model of Subjective WellBeing: The Discrepancy Between Specific and Global Domain Satisfaction. Journal of Personality, 69(4), 641-666.

Parker, S. L., Jimmieson, N. L., \& Johnson, K. M. (2013). General self-efficacy influences affective task reactions during a work simulation: the temporal effects of changes in workload at different levels of control. Anxiety, Stress \& Coping, 26(2), 217-239.

Pettit, J. W., Kline, J. P., Gencoz, T., Gencoz, F., \& Joiner Jr, T. E. (2001). Are happy people healthier? The specific role of positive affect in predicting self-reported health symptoms. Journal of Research in Personality, 35(4), 521-536.

Podsakoff, P. P. M., MacKenzie, S. S. B., Lee, J. Y., \& Podsakoff, N. P. (2003). Common method biases in behavioral research: a critical review of the literature and recommended remedies. Journal of Applied \ldots, 88(5), 879-903. https://doi.org/10.1037/00219010.88 .5 .879

Reise, S. P. (2012). The rediscovery of bifactor measurement models. Multivariate Behavioral Research, 47(5), 667-696.

Reise, S. P., Moore, T. M., \& Haviland, M. G. (2010). Bifactor models and rotations: Exploring the extent to which multidimensional data yield univocal scale scores. Journal of Personality Assessment, 92(6), 544-559. https://doi.org/10.1080/00223891.2010.496477

Renshaw, T. L. (2018). Psychometrics of the Revised College Student Subjective Wellbeing Questionnaire. Canadian Journal of School Psychology, 33(2), 136-149. https://doi.org/10.1177/0829573516678704 
Renshaw, T. L., \& Bolognino, S. J. (2016). The College Student Subjective Wellbeing Questionnaire: A Brief, Multidimensional Measure of Undergraduate's Covitality. Journal of Happiness Studies, 17(2), 463-484. https://doi.org/10.1007/s10902-014-96064

Renshaw, T. L., \& Chenier, J. S. (2018). Further validation of the Student Subjective Wellbeing Questionnaire: Comparing first-order and second-order factor effects on actual school outcomes. Journal of Psychoeducational Assessment, 36(4), 392-397.

Reyes-García, V., Angelsen, A., Shively, G. E., \& Minkin, D. (2018). Does Income Inequality Influence Subjective Wellbeing? Evidence from 21 Developing Countries. Journal of Happiness Studies. https://doi.org/10.1007/s10902-018-9992-0

Ryff, C. D., \& Keyes, C. L. M. (1995). The structure of psychological well-being revisited. Journal of Personality and Social Psychology, 69(4), 719.

Seligman, M. (2012). Flourish: A visionary new understanding of happiness and wellbeing. Simon and Schuster. Retrieved from https://scholar.google.com/scholar_lookup?hl=en\&publication_year=2011\&author=M.+ E. + P. + Seligman\&title $=$ Flourish

Seligman, M., \& Csikszentmihalyi, M. (2014). Positive psychology: An introduction. In Flow and the foundations of positive psychology (pp. 279-298). Springer.

Schmitt, N., \& Bradburn, J. C. (2018). An Ideal Student Factor and the validity of noncognitive measures of student potential. International Journal of Selection and Assessment, 26(24), 109-123. 
Singh, S., \& Aggarwal, Y. (2018). Happiness at work scale: Construction and psychometric validation of a measure using mixed method approach. Journal of Happiness Studies, 19(5), 1439-1463.

Smillie, L. D., Cooper, A. J., Wilt, J., \& Revelle, W. (2012). Do extraverts get more bang for the buck? Refining the affective-reactivity hypothesis of extraversion. Journal of Personality and Social Psychology, 103(2), 306-326. https://doi.org/10.1037/a0028372

Smyth, J. M., Zawadzki, M. J., Juth, V., \& Sciamanna, C. N. (2017). Global life satisfaction predicts ambulatory affect, stress, and cortisol in daily life in working adults. Journal of Behavioral Medicine, 40(2), 320-331.

Steel, P., Schmidt, J., \& Shultz, J. (2008). Refining the relationship between personality and subjective well-being. Psychological Bulletin. https://doi.org/10.1037/00332909.134.1.138

Steiger, J. H. (1990). Structural model evaluation and modification: An interval estimation approach. Multivariate Behavioral Research, 25(2), 173-180.

Takebayashi, Y., Tanaka, K., Sugiura, Y., \& Sugiura, T. (2018). Well-Being and Generalized Anxiety in Japanese Undergraduates: A Prospective Cohort Study. Journal of Happiness Studies, 19(3), 917-937. https://doi.org/10.1007/s10902-017-9852-3

Tellegen, A., Lykken, D. T., Bouchard, T. J., Wilcox, K. J., Segal, N. L., \& Rich, S. (1988). Personality similarity in twins reared apart and together. Journal of Personality and Social Psychology, 54(6), 1031-1039. https://doi.org/10.1037/0022-3514.54.6.1031 
Tett, R. P., \& Guterman, H. A. (2000). Situation Trait Relevance, Trait Expression, and CrossSituational Consistency: Testing a Principle of Trait Activation. Journal of Research in Personality, 34(4), 397-423. https://doi.org/10.1006/jrpe.2000.2292

Twenge, J. M., Joiner, T. E., Rogers, M. L., \& Martin, G. N. (2018). Increases in depressive symptoms, suicide-related outcomes, and suicide rates among US adolescents after 2010 and links to increased new media screen time. Clinical Psychological Science, 6(1), 3-17.

Vandenberg, R. J., \& Lance, C. E. (2000). A Review and Synthesis of the Measurement Invariance Literature: Suggestions, Practices, and Recommendations for Organizational Research. Organizational Research Methods, 3(1), 4-70. https://doi.org/10.1177/109442810031002

Weissman, M. M., Prusoff, B. A., \& Klerman, G. L. (1978). Personality and the prediction of long-term outcome of depression. The American Journal of Psychiatry.

Wilson, W. R. (1967). Correlates of avowed happiness. Psychological Bulletin, 67(4), 294-306. https://doi.org/10.1037/h0024431

Zhang, D. C., Highhouse, S., \& Nye, C. D. (2018). Development and validation of the General Risk Propensity Scale (GRiPS). Journal of Behavioral Decision Making. https://doi.org/10.1002/bdm.2102 
Table 1

Means, standard deviations, and inter correlations of variables

\begin{tabular}{|c|c|c|c|c|c|c|c|c|c|c|c|c|c|}
\hline Variable & $M$ & $S D$ & 1 & 2 & 3 & 4 & 5 & 6 & 7 & 8 & 9 & 10 & 11 \\
\hline 1. Overall Well-Being & 5.71 & 0.79 & $(.92)$ & & & & & & & & & & \\
\hline 2. School Connectedness & 5.44 & 1.10 & $.72 * *$ & $(.91)$ & & & & & & & & & \\
\hline 3. Academic Efficacy & 5.60 & 1.09 & $.77 * *$ & $.28 * *$ & $(.91)$ & & & & & & & & \\
\hline 4. Gratitude & 6.48 & 0.72 & $.71 * *$ & $.39 * *$ & $.50 * *$ & $(.90)$ & & & & & & & \\
\hline 5. Academic Satisfaction & 5.34 & 1.20 & $.85^{* *}$ & $.50 * *$ & $.56 * *$ & $.45^{* *}$ & $(.91)$ & & & & & & \\
\hline 6. Extraversion & 3.09 & 1.00 & $.24 * *$ & $.31^{* *}$ & .04 & $.18^{*}$ & $.19^{* *}$ & $(.79)$ & & & & & \\
\hline 7. Agreeableness & 3.92 & 0.75 & $.36^{* *}$ & $.26^{* *}$ & $.25^{* *}$ & $.34 * *$ & $.28 * *$ & $.25^{* *}$ & $(.78)$ & & & & \\
\hline 8. Conscientiousness & 3.68 & 0.80 & $.37 * *$ & .07 & $.56^{* *}$ & $.21 * *$ & $.27 * *$ & -.06 & $.20^{* *}$ & $(.73)$ & & & \\
\hline 9. Neuroticism & 2.90 & 0.86 & $-.23 * *$ & $-.23 * *$ & $-.17 *$ & -.07 & $-.19 * *$ & $-.15^{*}$ & .04 & $-.30 * *$ & $(.56)$ & & \\
\hline 10. Openness to Experience & 3.65 & 0.70 & .07 & .08 & .06 & .13 & -.01 & .10 & $.22 * *$ & .09 & $-.18^{*}$ & $(.86)$ & \\
\hline 11. Sex & 1.82 & 0.38 & $.20 * *$ & .12 & $.19^{*}$ & $.21 * *$ & .12 & .12 & $.22 * *$ & .03 & $.19^{*}$ & -.02 & \\
\hline 12. Age & 20.02 & 2.17 & .02 & -.02 & .07 & .11 & -.05 & -.03 & .04 & -.05 & -.11 & .13 & .01 \\
\hline
\end{tabular}

Notes. * indicates $p<.05 ; * *$ indicates $p<.01 . M$ and $S D$ are used to represent mean and standard deviation, respectively. Cronbach's alphas are in diagonals. Sex: $1=$ Male, $2=$ Female. 
Table 2.

Fit indices of the confirmatory factor analyses for the CSSWQ

\begin{tabular}{lccccc}
\hline Model & RMSEA & CFI & TLI & SRMR & $\Delta \chi^{2}$ \\
\hline One-factor model & 0.234 & 0.53 & 0.46 & 0.14 & $858.09^{*}$ \\
Four-factor model & 0.095 & 0.93 & 0.91 & 0.06 & $23.43^{*}$ \\
Second-order model & 0.088 & 0.94 & 0.92 & 0.07 & $79.84^{*}$ \\
Bifactor model & 0.065 & 0.97 & 0.95 & 0.07 & 0.05 \\
\hline Bifactor path model & 0.053 & 0.97 & 0.96 & &
\end{tabular}

Notes. *. $p<.01$, RMSEA. Root mean square error of approximation; TLI, Tucker-Lewis index; CFI, comparative fit index; SRMR, standard root mean square residual 
Table 3.

Factor loadings of the CSSWQ indicators in the bifactor model

\begin{tabular}{|c|c|c|c|c|c|c|}
\hline \# & Item & GWF & $\begin{array}{l}\text { School } \\
\text { Connectedness }\end{array}$ & $\begin{array}{l}\text { Academic } \\
\text { Efficacy }\end{array}$ & $\begin{array}{l}\text { College } \\
\text { Gratitude }\end{array}$ & $\begin{array}{l}\text { Academic } \\
\text { Satisfaction }\end{array}$ \\
\hline 1 & I feel like a real part of this university & 0.53 & 0.54 & & & \\
\hline 2 & People at this school are friendly to me & 0.58 & 0.66 & & & \\
\hline 3 & I can really be myself at this school & 0.63 & 0.37 & & & \\
\hline 4 & Other students here like me the way I am & 0.66 & 0.51 & & & \\
\hline 5 & I am a hard worker in my classes & 0.56 & & 0.64 & & \\
\hline 6 & I am a diligent student & 0.52 & & 0.67 & & \\
\hline 7 & I am an organized and effective student & 0.43 & & 0.68 & & \\
\hline 8 & I study well for my classes & 0.41 & & 0.72 & & \\
\hline 9 & I am so thankful that I'm getting a college education & 0.51 & & & 0.55 & \\
\hline 10 & $\begin{array}{l}\text { I am grateful to the professors and other students who have } \\
\text { helped me in classes }\end{array}$ & 0.51 & & & 0.71 & \\
\hline 11 & $\begin{array}{l}\text { I feel thankful for the opportunity to learn so many new } \\
\text { things }\end{array}$ & 0.56 & & & 0.66 & \\
\hline 12 & $\begin{array}{l}\text { I am grateful for the people who have helped me succeed } \\
\text { in college }\end{array}$ & 0.56 & & & 0.64 & \\
\hline 13 & I have had a great academic experience at this university & 0.86 & & & & 0.15 \\
\hline 14 & I am happy with how I've done in my classes & 0.63 & & & & 0.65 \\
\hline 15 & $\begin{array}{l}\text { I am satisfied with my academic achievements since } \\
\text { coming to this university }\end{array}$ & 0.53 & & & & 0.74 \\
\hline 16 & I am pleased with how my college education is going so far & 0.82 & & & & 0.40 \\
\hline
\end{tabular}

Notes. All factor loadings are statistically significant at $p<.05$; GWF: general wellbeing factor. 
Table 4.

Standardized path coefficients between latent factors of CSSWQ and the Big Five personality traits

\begin{tabular}{|c|c|c|c|c|c|}
\hline \multirow[t]{2}{*}{ Latent Factors of CSSWQ } & \multicolumn{5}{|c|}{ Big Five Dimensions } \\
\hline & Extraversion & Agreeableness & Conscientiousness & Neuroticism & Openness to Experience \\
\hline General Wellbeing Factor & $0.26 * *$ & $0.21 *$ & 0.09 & -0.09 & -0.06 \\
\hline School Connectedness & 0.07 & 0.10 & -0.11 & $-0.27 * *$ & 0.05 \\
\hline Academic Efficacy & -0.08 & 0.06 & $0.63 * *$ & 0.02 & 0.00 \\
\hline College Gratitude & -0.02 & $0.23 *$ & 0.10 & 0.02 & 0.09 \\
\hline Academic Satisfaction & -0.08 & 0.15 & $0.21 *$ & -0.17 & -0.14 \\
\hline
\end{tabular}

Notes. ${ }^{*}, \mathrm{p}<.05 ; * *, \mathrm{p}<.01$ 
Figure 1. Comparison between a second-order and bifactor model of CSSWQ
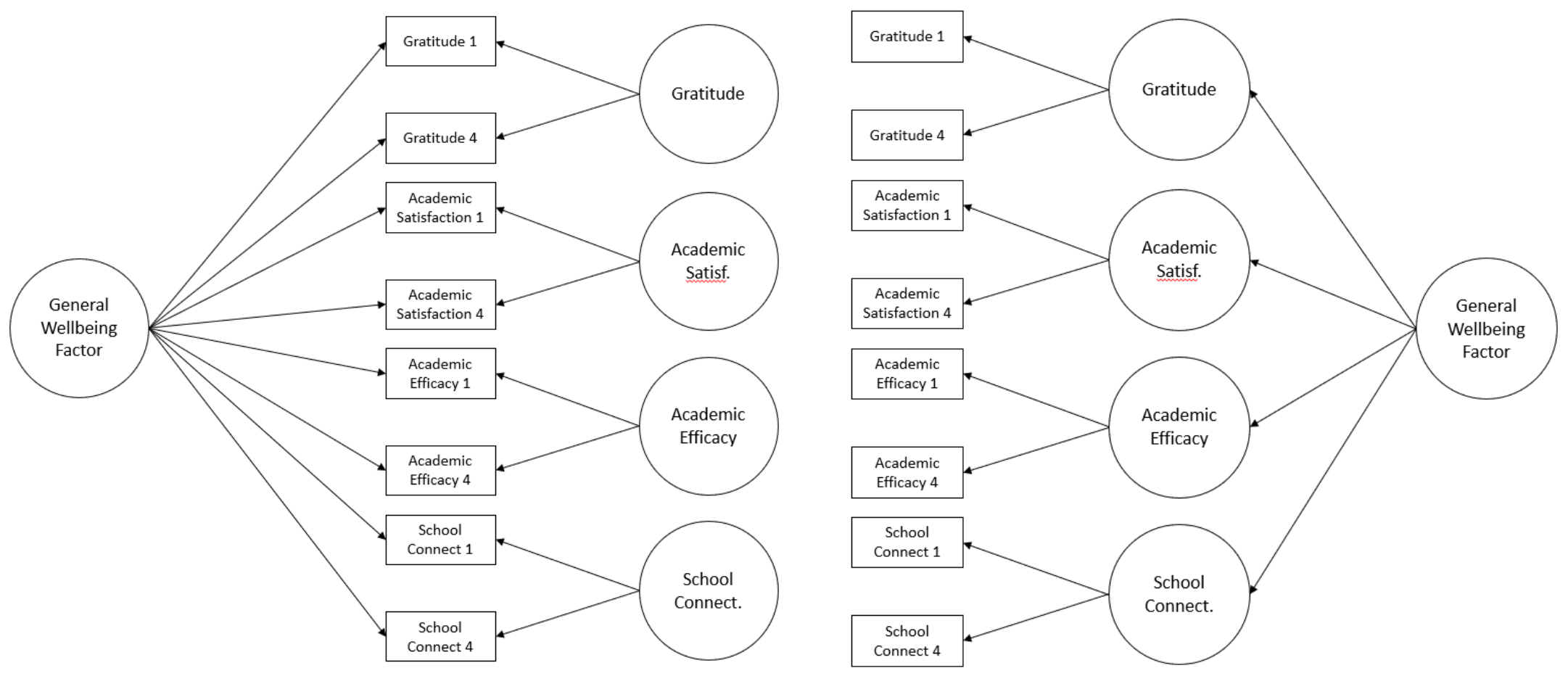

a. Bifactor Model

b. Second-order Model

Note. Not all indicators of CSSWQ are illustrated in the figure, for clarity. 
